\title{
Involvement of the Proximal C Terminus of the AMPA Receptor Subunit GluR1 in Dendritic Sorting
}

\author{
Francesca Ruberti and Carlos G. Dotti \\ Cell Biology and Biophysics Programme, European Molecular Biology Laboratory, 69112 Heidelberg, Germany
}

\begin{abstract}
Studies on dendritic sorting of transmembrane proteins in hippocampal neurons in culture have shown that these cells use similar mechanisms as epithelial cells to sort transmembrane proteins to the basolateral membrane domain. However, information is still scarce with regard to which amino acidic sequences are required for dendritic sorting in neurons. The glutamate receptor 1 (GluR1) subunit of the AMPA receptor is present on the dendritic compartment of hippocampal neurons in culture. To identify the GluR1 sorting signal responsible for dendritic targeting, we have expressed the wild-type GluR1, a deletion mutant in the $\mathrm{C}$-terminal cytoplasmic tail, and chimeric GluR1 proteins in hippocampal neurons using a calcium phosphate transfection method. The recombinant full-length GluR1 is polarized to the dendritic domain. Truncated GluR1 with a
\end{abstract}

deletion of the C-terminal cytoplasmic tail is still delivered to the somatodendritic domain. However a chimeric protein made of the luminal and transmembrane domain of the influenza virus hemagglutinin ( $\mathrm{HA})$ fused to the GluR1 C-terminal cytoplasmic tail (HaemR1) is detected in the somatodendritic domain. This finding indicates that the GluR1 C-terminal cytoplasmic tail contains a dendritic sorting signal, which redirects the axonal or axonal-dendritic protein HA to the dendritic compartment exclusively. Deletion analysis of HaemR1 shows that the proximal segment of the GluR1 C-terminal cytoplasmic tail contains a novel dendritic sorting signal.

Key words: dendrites; sorting; hippocampal neurons; GluR1; axonal; hemagglutinin
In neurons, as in any other polarized cell, proper function is primarily dependent on the correct segregation of membrane proteins to different cellular domains. How neurons sort proteins to specialized domains and how this differential protein distribution is maintained are only beginning to be understood. Studies performed in cultured hippocampal neurons during the last 10 years suggested that neurons can make use of different intracellular pathways to accomplish polarized segregation of membrane proteins (Dotti and Simons, 1990; Winckler and Mellman, 1999). For example, the axonal protein Ng-CAM (the chicken homologue of L1) is delivered directly to the axonal surface immediately after synthesis in the cell body, and the transferrin receptor, the polymeric $\mathrm{Ig}$ receptor $(\mathrm{p} \operatorname{IgR})$, the low-density lipoprotein receptor (LDLR) and the metabotropic glutamate receptor 2 (mGluR2) are instead delivered directly to the dendritic domain (de Hoop et al., 1995; West e al., 1997a; Jareb and Banker, 1998; Stowell and Craig, 1999). These results suggested the existence of a direct pathway from the cell body to either axons or dendrites, in analogy to what happens in epithelial cells, where apical and basolateral proteins are sorted at the level of the Golgi apparatus. However, other constitutively axonal proteins, such as synaptophysin, synaptotagmin, and mGluR7, when overexpressed, result in the filling of both axon and dendrites (West et al., 1997b; Stowell and Craig, 1999; Kaether et al., 2000b). Yet another pathway seems to be used by amyloid precursor protein (APP)

Received Feb. 4, 2000; revised March 9, 2000; accepted March 24, 2000.

F.R. was a recipient of a European Community long-term fellowship. We thank B. Hellias and E. Cassin for technical assistance, Peter Scheiffele for hemagglutinin cDNA and also for advice, and C. Kaether, E. Piddini, M. D. Ledesma, and F. Bradke for discussions and advice.

Correspondence should be addressed to Carlos G. Dotti, Cell Biology and Biophysics Programme, European Molecular Biology Laboratory, 69112 Heidelberg, Germany. E-mail: Dotti@embl-heidelberg.de.

Copyright (C) 2000 Society for Neuroscience $0270-6474 / 00 / 200001-05 \$ 15.00 / 0$ and a mutant form of the pIgR ( $\Delta 655-668$ pIgR mutant). When overexpressed, these proteins appear initially in the axonal domain and at later times also in the dendrites (de Hoop et al., 1995; Simons et al., 1995). The latter two types of distribution suggest the existence of a post-Golgi sorting organelle responsible for polarized distribution (in the dendritic surface or endosomes for synaptophysin and synaptotagmin and in the axonal surface or endosomes for APP).

The work on the dendritic sorting in hippocampal neurons highlighted the role of specific amino acid motifs in the cytoplasmic tail of polarized proteins. For example, the transferrin receptor, the LDLR, and the glycine transporter require tyrosine or dileucine motifs located in the cytoplasmic side close to the transmembrane domain for proper dendritic delivery (West et al., 1997a; Jareb and Banker, 1998; Poyatos et al., 2000). Different from these motifs, the neuronal mGluR2 uses yet a different sorting signal for its dendritic delivery (Stowell and Craig, 1999).

To advance our understanding in the field of neuronal membrane asymmetry, we have now studied the sorting signals required for the dendritic distribution of the AMPA GluR1.The AMPA receptors are ionotropic glutamate receptors, which are

This article is published in The Journal of Neuroscience, Rapid Communications Section, which publishes brief, peerreviewed papers online, not in print. Rapid Communications are posted online approximately one month earlier than they would appear if printed. They are listed in the Table of Contents of the next open issue of JNeurosci. Cite this article as: JNeurosci, 2000, 20:RC78 (1-5). The publication date is the date of posting online at www.jneurosci.org.

http://www.jneurosci.org/cgi/content/full/4218 
involved in fast excitatory synaptic transmission in the brain (Hollmann and Heinemann, 1994). Functional AMPA receptors are multimeric complexes formed by different combinations of the homologous subunits GluR1-4, which share 60-70\% identity at the level of the primary sequence (Mano and Teichberg, 1998). Numerous studies have shown that in neurons AMPA receptors are highly concentrated at excitatory synapses on dendritic spines and shafts.

In the present study we show that overexpressed wild-type (wt) GluR1 and a truncated mutant with a deletion in the $\mathrm{C}$-terminal cytoplasmic tail are delivered to the somatodendritic domain in hippocampal neurons in culture. However, the addition of the GluR1 C-terminal cytoplasmic tail redirects the sorting of a axonal or axonal-dendritic protein to the dendritic domain only. Deletion mutants of the chimeric protein allowed us to demonstrate that the proximal segment of the GluR1 C-terminal cytoplasmic tail contains a novel dendritic sorting signal.

\section{MATERIALS AND METHODS}

Plasmids. Human GluR1 flip was obtained from American Type Culture Collection (Manassas, VA); mGluR2 cDNA was kindly provided from S. Nakanishi (Kyoto University, Kyoto, Japan); and influenza hemagglutinin (HA) [A/Japan/305 (H2)] and hemagglutinin tail minus cDNAs were kindly provided from P. Scheiffele (European Molecular Biology Laboratory). All the cDNAs were subcloned in pcDNA3 mammalian expression vector (Invitrogen, San Diego, CA). For GluR1 constructs, amino acid numbers refer to published sequence excluding the signal peptide. Influenza hemagglutinin is listed with the amino acid number including the signal sequence.

A two-step PCR strategy was used to insert an HA epitope (YPYDVPDYA) in human GluR1 (hGluR1). In the first step, two distinct PCR reactions, using as template an $\mathrm{HA} / \mathrm{mGluR} 2$ construct (available in our laboratory), and hGluR1, respectively, were performed. One PCR reaction produced a fragment containing a $5^{\prime}$ EcoRI restriction site, the 5' untranslated region, the signal sequence of mGluR2, and the HA tag; the other reaction, using as template hGluR1, produced a PCR fragment containing a $5^{\prime} \mathrm{HA}$ tag and the hGluR1 coding sequence from the first amino acid past the signal sequence (Sun et al., 1992) to the unique ApaI restriction site. In the second step, the two PCR products, which contain a $30 \mathrm{bp}$ sequence overlap, were mixed together and amplified using external primers. The PCR product was cut with EcoRI and ApaI and subcloned in hGluR1 pCDNA3. The deletion mutant HAhGluR1(d816888 ) was produced by PCR starting from HA-hGluR1. The two-step PCR strategy has been also used to produce the chimeric construct HaemR1 (HA, 1-535; hGluR1flip, 809-888) and its deletion mutants HaemR1 proximal (HA, 1-535; hGluR1flip, 809-849) and HaemR1 distal (HA, 1-535; hGluR1flip, 809-815, 848-888).

All of the mutagenized cDNAs were sequenced by the EMBL sequences service to ensure that unwanted mutations had been introduced during PCR.

Neuron culture and immunocytochemistry. Primary hippocampal neurons were prepared from embryonic day 18 rat brains as described by Goslin and Banker (1991). For immunocytochemistry experiments cells grown on glass coverslips were fixed with $4 \%$ paraformaldehyde in PBS for $15 \mathrm{~min}$. Paraformaldehyde was quenched with $50 \mathrm{~mm}$ ammonium chloride in PBS for $10 \mathrm{~min}$. Then the cells were permeabilized with $0.2 \%$ Triton X-100 in PBS for $5 \mathrm{~min}$. To prevent unspecific staining, the cells were incubated with blocking solution ( $2 \%$ BSA, $2 \%$ FCS, and $0.2 \%$ fish skin gelatin) in PBS for $30 \mathrm{~min}$. For double labeling the cells were incubated with the primary antibodies diluted in $10 \%$ blocking solution in PBS for $1 \mathrm{hr}$ at room temperature or overnight at $4 \mathrm{C}$. Cells were washed three times with PBS (5 min each) and then incubated with appropriate fluorochrome-conjugated secondary antibodies diluted in $10 \%$ blocking solution in PBS for 20-30 min at room temperature. After three washes with PBS the coverslips were mounted with Mowiol (Merck, Darmstadt, Germany) containing $100 \mathrm{mg} / \mathrm{ml}$ 1,4-diazabicyclo[2.2.2]octane (Sigma, St. Louis, MO) as an anti-fading agent.

The following primary antibodies have been used: mouse monoclonal antibody anti-HA (12CA5; Roche Molecular Biochemicals, Mannheim, Germay), polyclonal rabbit antibody 514 to MAP2 (a gift from C. Sanchez, Centro de Biologia Molecular, Madrid, Spain), polyclonal rabbit antibody anti-hemagglutinin (kindly provided by Peter Scheiffele, European Molecular Biology Laboratory), and mouse monoclonal antibody to MAP-2 (anti-MAP-2; Roche).

Calcium phosphate transfection method. Neurons 7-11 d in vitro (DIV) bearing coverslips were transferred from the home dish and flipped cell side-up to $35 \mathrm{~cm}$ dishes with $2 \mathrm{ml}$ of $\mathrm{N} 2$ glia-conditioned medium. The DNA for transfection was prepared by EndoFree plasmid maxi kit (Qiagen, Hilden, Germany). Two to $5 \mu \mathrm{g}$ of DNA were mixed with $6 \mu \mathrm{l}$ of $\mathrm{CaCl}_{2}$ solution $(2.5 \mathrm{M})$ to a final volume of $60 \mu \mathrm{l}$ and then mixed with $60 \mu \mathrm{l}$ of $2 \times \mathrm{BBS}\left(280 \mathrm{~mm} \mathrm{NaCl}, 1.5 \mathrm{~mm} \mathrm{Na}_{2} \mathrm{HPO}_{4}\right.$, and $50 \mathrm{~mm} \mathrm{N,N-}$ bis[2-hydroxyethyl]-2-amino-ethanesulfonic acid $\mathrm{pH}$ 7.1) and immediately $(<2 \mathrm{~min})$ added to the neurons. The dishes were incubated at $37^{\circ} \mathrm{C}$ and $2.5 \% \mathrm{CO}_{2}$ until a fine precipitate was formed. Cells were washed with HBS (135 mM NaCl, 20 mM HEPES, $4 \mathrm{~mm} \mathrm{KCl}, 1 \mathrm{~mm} \mathrm{Na}_{2} \mathrm{HPO}_{4}, 2$ $\mathrm{mM} \mathrm{CaCl}_{2}, 1 \mathrm{~mm} \mathrm{MgCl}$, and $10 \mathrm{~mm}$ glucose) and cultured in the original medium at $37^{\circ} \mathrm{C}$ and $5 \% \mathrm{CO}_{2}$ for $24-48 \mathrm{hr}$ (Kaether et al., 2000a).

Quantitation of hemagglutinin distribution. Eleven DIV transfected neurons were analyzed by immunofluorescence by using antibodies against the dendritic marker MAP2 and against hemagglutinin. Phasecontrast, MAP2, and hemagglutinin images were captured for each transfected cell with a charged-coupled device camera (4910; Cohu, San Diego) connected to a Macintosh computer (Power Macintosh 7300/166; Apple, Cupertino, CA) equipped with an image recorder (LG3; Scion, Frederick, MD). Unprocessed images were stored by using NIH Image. For the images with hemagglutinin labeling, axonal and dendritic domains were identified by comparison with the corresponding MAP2 and phase-contrast images. Therefore, the area of axonal and dendritic segments was delineated, and the hemagglutinin signal within the area was quantitated (mean pixel intensity/area). Axonal and dendritic area were normalized to the same size, and the percentage of labeling intensity in dendrites and axons was calculated.

\section{RESULTS}

\section{The wild-type human GluR1 and a C-terminal deletion mutant are sorted to the dendrites of cultured hippocampal neurons}

The sorting of human GluR1 was analyzed in 9 DIV hippocampal neurons in culture. An HA epitope tag was introduced at the N terminus of human GluR1 to distinguish recombinant from endogenous proteins. A calcium phosphate precipitation expression system was used to study the polarization of newly synthesized recombinant proteins. The dendrites of the cells were identified by labeling with an antibody against MAP2, a cytoskeletal dendritic protein (Bernhardt and Matus, 1984). Indirect immunofluorescence microscopy after $24-48 \mathrm{hr}$ of transfection with the wt HA-hGluR1(1-888) revealed an almost dendritic distribution (Fig. 1A-D). Indeed, MAP2 and HA exactly colocalized in all transfected cells. The distribution of the overexpressed human form of the receptor is consistent with the dendritic distribution of the endogenous receptor in these cells (results not shown; but see Craig et al., 1993). Furthermore, this result proves the validity of the method used to further characterize the sorting signals responsible for dendritic sorting of this subunit. Given that most dendritic membrane proteins studied until now contain sorting information within the cytoplasmic domain, we investigated whether this is also the case for the GluR1 subunit. To test the involvement of the C-terminal cytoplasmic tail, we expressed a deletion mutant truncated seven amino acids after the fourth transmembrane domain, HA-hGluR1(d816-888), into hippocampal neurons and analyzed the distribution by immunofluorescence microscopy. Surprisingly, the distribution of the overexpressed mutant protein HA-hGluR1(d816-888) was similar to that of the wild-type protein and appeared exclusively in the dendritic domain (Fig. 1E,F). Although the simplest interpretation of these results would be that dendritic delivery does not require the $\mathrm{C}$ terminus, it could also be that the deletion construct is sorted via interaction with endogenous subunits during pro- 


$$
\text { A }
$$

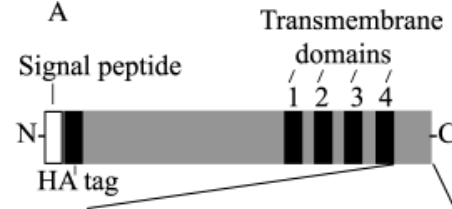

EFCYKSRSKRMKGFCLIPQQSIN EAIRTSTLPRNSGAGASSGGSGE NGRVVSHDFPKSMQSIPCMSHSS GMPLGATGL

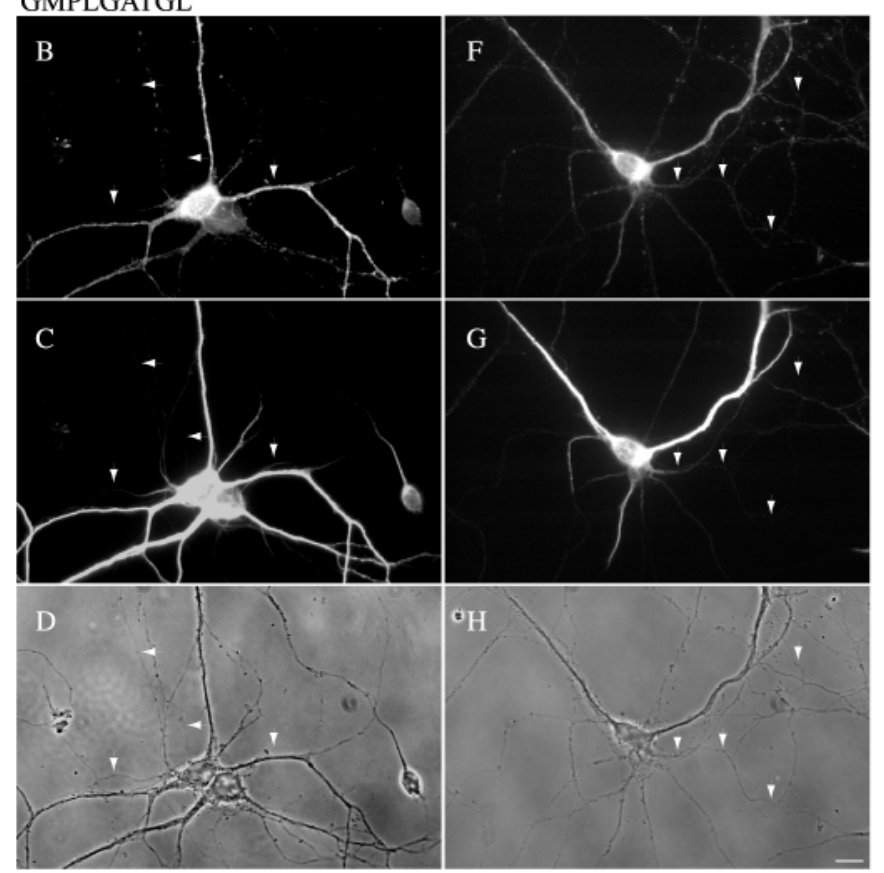

Figure 1. Dendritic distribution of expressed hGluR1 constructs in 9 DIV hippocampal neurons. $A, E$, Scheme of wt HA-hGluR1 and HA-hGluR1(d816-888). The amino acid sequences of the C-terminal cytoplasmic tail of wild-type and mutant human HA-GluR1 are shown in single-letter code. $B-D, F-H$, Nine DIV neurons were transfected with wt HA-GluR1 $(B-D)$ or HA-hGluR1(d816-888) $(F-H)$ and fixed $48 \mathrm{hr}$ later. The neurons were analyzed by immunofluorescence using an antibody against the HA tag of the recombinant hGluR proteins $(B$, $F)$ and antibodies against a dendritic marker, MAP2 $(C, G)$. As shown in $B$, the anti-HA antibody gave specific labeling of the transfected cell on the left and only background labeling of the nontransfected cell on the right. $D$, $H$, Phase-contrast images indicating the cell body, dendrites, and putative axons (arrows) of cells of the same fields $(D, H)$. Note that the expressed full-length HA-hGluR1 and HAhGluR1(d816-888) gave the same distribution pattern of the cytoskeletal protein MAP2. All of the axons in the micrographs are negative for MAP2 and HA. Scale bar, $10 \mu \mathrm{m}$.

cessing along the secretory pathway. We tried to titrate out the endogenous subunits increasing the level of expression of HAhGluR1(d816-888), but in this case, in most of the transfected cells the mutant protein was retained in the endoplasmic reticulum, and in the remaining cells it was still delivered to the somatodendritic domain, suggesting that only correctly folded, oligomerized protein can leave the secretory pathway.

\section{The $\mathbf{C}$ terminus of GluR1 is sufficient to direct an axonal protein to the dendritic domain of cultured hippocampal neurons}

To circumvent the problem of oligomers, we constructed a chimeric protein composed of the $\mathrm{C}$ terminus of GluR1 and the ectodomain and transmembrane domain of influenza virus glycoprotein HA. We called this chimera HaemR1. In hippocampal
A

$\mathrm{E}$
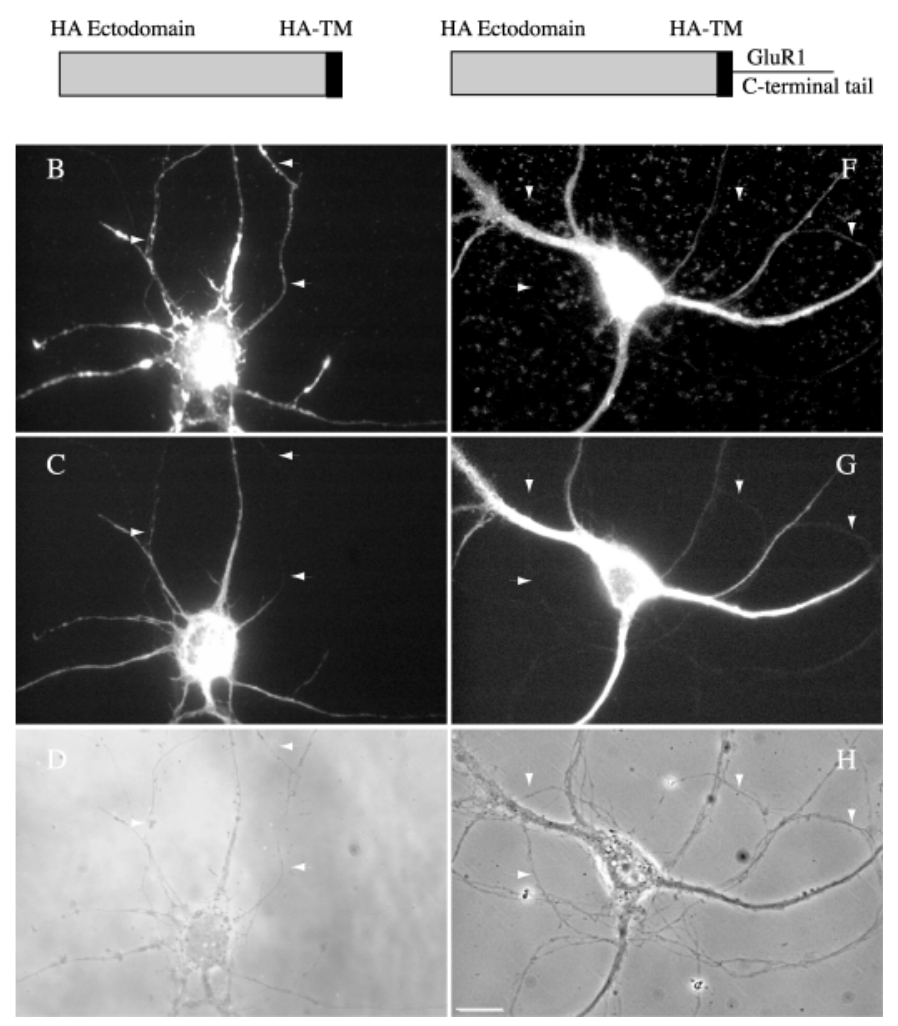

Figure 2. Distribution of HA tail minus protein and HaemR1 chimera in 11 DIV hippocampal neurons. $A, E$, Scheme of HA tail minus and HaemR1 chimera. $B, C, F, G$, Double immunofluorescence performed $10-12 \mathrm{hr}$ after transfection using polyclonal rabbit antibodies against the viral protein hemagglutinin $(B, F)$ and monoclonal antibody against a dendritic marker, MAP-2 $(C, G) . D, H$, Phase-contrast images. Putative axons of transfected cells are indicated (arrows). The hemagglutinin tail minus protein is distributed to both the axonal and the dendritic compartments, whereas the HaemR1 chimera is targeted to the dendritic compartment and excluded from the axon. Scale bar, $10 \mu \mathrm{m}$.

neurons HA is directed to the axon but in some neurons is also dendritic (Jareb and Banker, 1998; Ledesma et al., 1998). Hemagglutinin tail minus and HaemR1 were transiently transfected into 10-11 DIV hippocampal neurons by the $\mathrm{CaPO}_{4}$ method and fixed 10-12 hr later. Most of the neurons expressing the tail-less HA showed clear axonal labeling and dendritic-positive patches (Fig. 2A-D). Different from the tail-less HA, HaemR1 was exclusively found on the dendritic compartment (Fig. 2E,F). These data imply that the GluR1 cytoplasmic tail contains a cis-acting dendritic sorting signal(s), sufficient to direct a heterologous protein from primarily axonal and dendritic distribution to the dendritic compartment exclusively.

\section{The proximal segment of the GluR1 C terminus contains a somatodendritic sorting signal}

To define with more precision the region of the GluR1 C-terminal cytoplasmic tail involved in dendritic sorting, we made two different deletion mutants in the GluR1 cytoplasmic tail of the HaemR1 construct: HaemR1 proximal and HaemR1 distal. HaemR1 proximal contains 39 amino acids of GluR1 C-terminal cytoplasmic tail proximal to the transmembrane region; HaemR1 distal is complementary to the previous one and has the last 41 amino acids of the GluR1 C-terminal cytoplasmic tail.

HaemR1 proximal and distal were separately transfected in 
A

Proximal

E
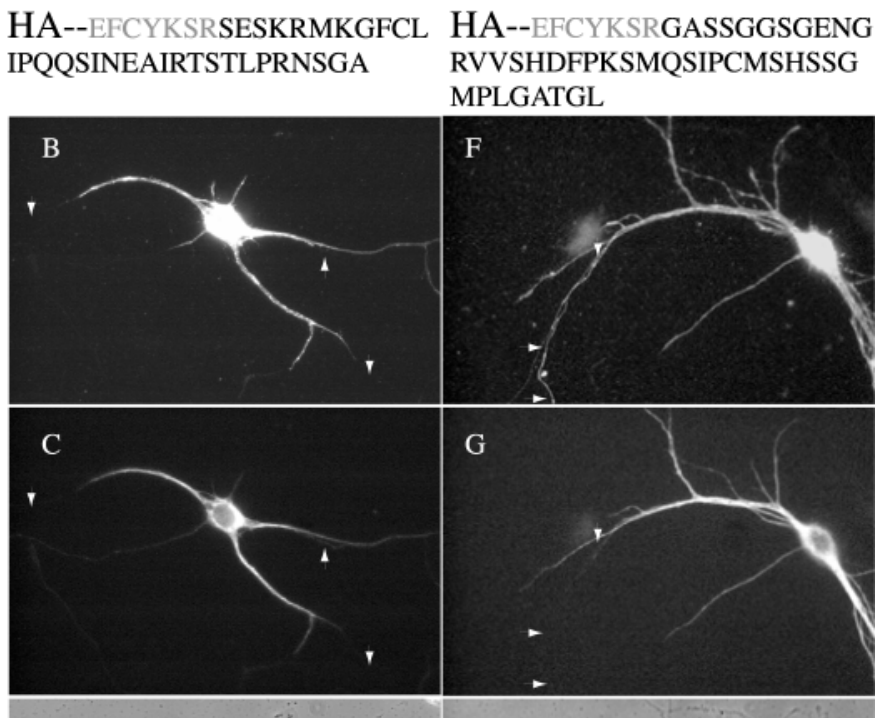

G

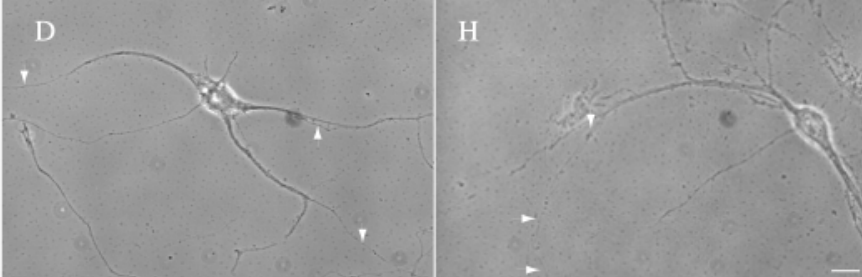

Figure 3. HaemR1 proximal but not HaemR1 distal is sorted to the somatodendritic domain. $A, E$, Cytoplasmic domain amino acid sequences of the chimeric proteins HaemR1 proximal and distal consisting of the ecto and transmembrane domains of HA and GluR1 C-terminal cytoplasmic domain sequences are shown in single-letter code. The first seven amino acids of the GluR1 cytoplasmic tail, common to the two constructs, are indicated in gray. $B, C, F, G$, Double immunofluorescence performed $12 \mathrm{hr}$ after transfection using polyclonal rabbit antibodies against the viral protein hemagglutinin $(B, F)$ and a monoclonal antibody against a dendritic marker, MAP-2 $(C, G) . D, H$, Phase-contrast images of cell body, dendrites, and putative axons (arrows) of HaemR1 proximaland HaemR1 distal-positive cells. As shown in these representative micrographs, HaemR1 proximal contains sorting information sufficient for dendritic targeting; instead, HaemR1 distal is distributed to the dendritic and axonal domains. Bar, $10 \mu \mathrm{m}$.

10-11 DIV hippocampal neurons and the distribution of the mutant protein analyzed by immunofluorescence microscopy. The results of such experiments are shown in Figure 3, and the quantititation of protein distribution is shown in Figure 4. The HaemR1 proximal protein colocalized perfectly with MAP2 and is therefore efficiently delivered to the somatodendritic domain. In contrast, the HaemR1 distal chimeric protein filled both MAP2-positive and MAP2-negative processes, thus behaving like numerous overexpressed axonal proteins do (West et al., 1997b; Jareb and Banker, 1998; Kaether et al., 2000b). The application of a quantitative method on 24 transfected cells (from two different experiments) for the different chimeric constructs revealed that $>90 \%$ of HaemR1 and HaemR1 proximal protein was in the dendritic compartment, whereas for HaemR1 distal $40 \%$ of the protein was axonal and $60 \%$ was dendritic (Fig. 4).

\section{DISCUSSION}

In this work we show that the GluR1 subunit contains dendritic sorting information in the proximal region of the $\mathrm{C}$ terminus.

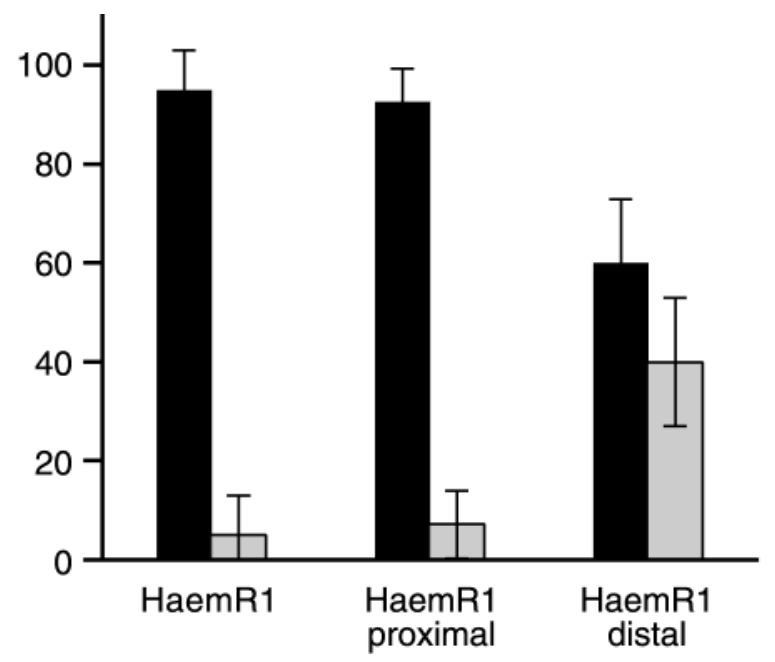

Figure 4. Percentage of dendritic and axonal distribution mediated by the GluR1 C-terminal tail and its proximal and distal domains. Indicated is the percentage of the intensity of axonal (gray bars) and dendritic (black bars) labeling for HaemR1 chimera, HaemR1 proximal and HaemR1 distal (mean $\pm \mathrm{SD} ; n=24$ cells obtained from the transfection of neurons from two different cultures). The intensity of the labeling for HaemR1 and HaemR1 proximal was much higher in the dendritic compartment than in the axon, whereas the intensity of labeling for HaemR1 distal in the dendrite was comparable with that in the axon.

This is based on the fact that this region was able to direct the hemagglutinin ectodomain-transmembrane construct from axonal-dendritic to exclusively dendritic. Although the results with this chimera were clear, it is necessary to discuss why the absence of this region in the GluR1 protein itself did not affect proper dendritic sorting. It is possible that the lack of effect was attributable to interaction with the endogenous protein. Indeed, the assembly of multimeric channels may occur in the endoplasmic reticulum, as has been demonstrated for the acetylcholine receptor (Gelman et al., 1995). Alternatively, other signals in the native protein may play a role in dendritic sorting, and these might become activated in the absence of the proximal $\mathrm{C}$ terminus. If this is true, it would mean that the GluR1 contains redundant dendritic sorting information, similar to what has been observed in basolaterally sorted proteins (Matter et al., 1992).

A second aspect of our findings is that the sequence in the proximal segment of the GluR1 C-terminal cytoplasmic tail involved in dendritic delivery does not contain previously described (Tyr or Leu-Leu) dendritic sorting motifs (Keller and Simons, 1997; Jareb and Banker, 1998; Poyatos et al., 2000). Although the proximal segment contains a Leu-Ile motif, deletion of this region did not affect dendritic sorting (results not shown). Because the sequence here described is also unrelated to that found in another postsynaptic receptor, a metabotropic glutamate receptor subunit (Stowell et al., 1999), we can conclude that the sorting of membrane proteins to dendrites is controlled quite specifically, almost in a protein-protein fashion, which might reflect transport in different vesicles. For the cell such diversity of signals could represent a mechanism to guarantee the precise delivery to different membrane subdomains, i.e., different dendritic spines, different parts of individual dendritic spines, and the dendritic shaft. This also implies that the sorting machinery, i.e., cytoplasmic factors interacting with the sorting signal, also would be protein-specific.

A third conclusion from our results is that the well described 
PSD-95/Dlg/ZO-1 (PDZ) motif present in the final region of the C terminus (Kim and Huganir, 1999) is not involved in sorting. Indeed, we show that deletion of this segment (distal mutant) does not alter proper dendritic distribution. This would point to a role of the PDZ domain for proper retention of the protein, for example, via interaction with the synaptic-associated protein SAP97 (Leonard et al., 1998), but not for its delivery from the cell body to dendrites.

Despite the clustered synaptic localization of endogenous GluR1 in cultured hippocampal neurons as reported by Craig et al. (1993), we were unable to observe such clustering of the recombinant HA-hGluR1(1-888). However, overexpression in hippocampal neurons of another synaptic protein, mGluR2, reproduces dendritic sorting but not synaptic clustering, suggesting that this process must involve late steps in targeting, which could be more susceptible to saturation respect to dendritic sorting (Stowell and Craig, 1999).

The molecular mechanism by which the proximal region of the $\mathrm{C}$ terminus here identified controls dendritic delivery remains to be resolved. One possible mechanism would be via interaction with the membrane cytoskeletal protein $4 \mathrm{~N} 1$, which has been recently shown to bind to a membrane proximal region of the GluR1 cytoplasmic tail (Shen et al., 1999; Walensky et al., 1999). However, this remains to be demonstrated. Our results should facilitate the isolation of the cytosolic receptor(s) responsible for GluR1 sorting. Indeed, the proximal region of the $\mathrm{C}$ terminus here reported to have dendritic sorting information can be used to identify interacting components, either in the form of glutathione $S$-transferase fusion peptides or as bait for the yeast two-hybrid screen.

\section{REFERENCES}

Bernhardt R, Matus A (1984) Light and electron microscopic studies of the distribution of microtubule-associated protein 2 in rat brain: a difference between dendritic and axonal cytoskeletons. J Comp Neurol 226:203-221.

Craig AM, Blackstone CD, Huganir RL, Banker G (1993) The distribution of glutamate receptors in cultured rat hippocampal neurons: postsynaptic clustering of AMPA-selective subunits. Neuron 10:1055-1068.

de Hoop M, von Poser C, Lange C, Ikonen E, Hunziker W, Dotti CG (1995) Intracellular routing of wild-type and mutated polymeric immunoglobulin receptor in hippocampal neurons in culture. J Cell Biol 130:1447-1459.

Dotti CG, Simons K (1990) Polarized sorting of viral glycoproteins to the axon and dendrites of hippocampal neurons in culture. Cell 62:63-72.

Gelman MS, Chang W, Thomas DY, Bergeron JJ, Prives JM (1995) Role of the endoplasmic reticulum chaperone calnexin in subunit folding and assembly of nicotinic acetylcholine receptors. J Biol Chem 270:15085-15092.

Goslin K, Banker G (1991) Rat hippocampal neurons in low density culture. In: Culturing nerve cells (Banker G, Goslin K, eds), pp 251281. Cambridge, MA: MIT.

Hollmann M, Heinemann S (1994) Cloned glutamate receptors. Annu Rev Neurosci 17:31-108.

Jareb M, Banker G (1998) The polarized sorting of membrane proteins expressed in cultured hippocampal neurons using viral vectors. Neuron 20:855-867.

Kaether C, Kohrmann M, Dotti CG, Ruberti F (2000a) Transfection methods for neurons in primary culture. Cell Mol Methods Neurobiol Res, in press.

Kaether C, Skehel P, Dotti CG (2000b) Axonal membrane proteins are transported in distinct carriers: a 2-color video microscopy study in cultured hippocampal neurons. Mol Biol Cell 11:1213-1224.

Keller P, Simons K (1997) Post-Golgi biosynthetic trafficking. J Cell Sci 110:3001-3009.

Kim JH, Huganir RL (1999) Organization and regulation of proteins at synapses. Curr Opin Cell Biol 11:248-254.

Ledesma MD, Simons K, Dotti CG (1998) Neuronal polarity: essential role of protein-lipid complexes in axonal sorting. Proc Natl Acad Sci USA 95:3966-3971.

Leonard AS, Davare MA, Horne MC, Garner CC, Hell JW (1998) SAP97 is associated with the alpha-amino-3-hydroxy-5-methylisoxazole4-propionic acid receptor GluR1 subunit. J Biol Chem 273:19518-19524.

Mano I, Teichberg VI (1998) A tetrameric subunit stoichiometry for a glutamate receptor-channel complex. NeuroReport 9:327-331.

Matter K, Hunziker W, Mellman I (1992) Basolateral sorting of LDL receptor in MDCK cells: the cytoplasmic domain contains two tyrosine-dependent targeting determinants. Cell 71:741-753.

Poyatos I, Ruberti F, Dotti CG, GimEnez CG, Zafra F (2000) Discrete structural domains determine somatodendritic and basolateral sorting in the glycine transporter GLYT1. Mol Cell Neurosci 15:99-111.

Shen L, Walensky LD, Liang F, Snyder SH, Huganir R (1999) Interaction of two homologues of the erythrocyte membrane cytoskeletal protein 4.1 , protein $4.1 \mathrm{G}$ and $4.1 \mathrm{~N}$ with AMPA receptors. Soc Neurosci Abstr 25:1237.

Simons M, Ikonen E, Tienari PJ, Cid-Arregui A, Monning U, Beyreuther K, Dotti CG (1995) Intracellular routing of human amyloid protein precursor: axonal delivery followed by transport to the dendrites. J Neurosci Res 41:121-128.

Stowell JN, Craig AM (1999) Axon/dendrite targeting of metabotropic glutamate receptors by their cytoplasmic carboxy-terminal domains. Neuron 22:525-536.

Sun W, Ferrer-Montiel AV, Schinder AF, McPherson J, Evans GA, Montal M (1992) Molecular cloning, chromosomal mapping, and functional expression of human brain glutamate receptors. Proc Natl Acad Sci USA 89:1443-1447.

Walensky LD, Blackshaw S, Liao D, Watkins CC, Weier HU, Parra M, Huganir RL, Conboy JG, Mohandas N, Snyder SH (1999) A novel neuron-enriched homolog of the erythrocyte membrane cytoskeletal protein 4.1. J Neurosci 19:6457-6467.

West AE, Neve RL, Buckley KM (1997a) Identification of a somatodendritic targeting signal in the cytoplasmic domain of the transferrin receptor. J Neurosci 17:6038-6047.

West AE, Neve RL, Buckley KM (1997b) Targeting of the synaptic vesicle protein synaptobrevin in the axon of cultured hippocampal neurons: evidence for two distinct sorting steps. J Cell Biol 139:917-927.

Winckler B, Mellman I (1999) Neuronal polarity: controlling the sorting and diff usion of membrane components. Neuron 23:637-640. 